\title{
Research on the construction of Economic Belt along the East Longhai
}

\author{
Li Yinguo \\ School of Business Jiangsu Normal University \\ XuZhou, China \\ E-mail: liyinguocumt@sina.com
}

\author{
Li Tingting \\ School of Business Jiangsu Normal University \\ XuZhou, China \\ E-mail: xsdltt@163.com
}

\begin{abstract}
In order to make Jiangsu better into the national strategy of "one belt and one road", the economic development level of the northern Jiangsu should be improved. The paper describes the current situation of economic and social development of areas along the East Longhai Economic Belt, and compares the economic belt along the East Longhai with the economic belt along the Yangtze River from different aspects. Although the socialeconomic development of the East Longhai Economic Belt has some slight advantages, there is a big gap between the economic belt along the East Longhai and the Yangtze River. The importance of the construction is to create a vibrant urban axis, and to improve the regional comprehensive development capacity of Xuzhou and Lianyungang.
\end{abstract}

Keywords-East Longhai Economic Belt; Yangtze River; Economic Belt; Towns Axis; One Belt and One Road

\section{INTRODUCTION}

Along the East Longhai Economic Belt includs the following cities, such as Xuzhou, Lianyungang two central cities and Tongshan, Pizhou, Xinyi, the east Sea and other towns around the region, located in the eastern end of the new Eurasian Continental is an important component of the new Silk Road and plays an important role in the development of northern Jiangsu and the notional development strategy. August 2015, the Jiangsu provincial government in the strategy report "One Belt and One Road" proposed to upgrade the industrial belt along the east Longhai into economic belt, reflecting the deepening of industrial layout from the simple to the economic layout direction and expand the scope to centered on Xuzhou, Lianyungang and are closely linked with the Yancheng, Huai'an, Suqian and other regions, making it become the new economic growth pole in the "One Belt and One Road" strategic layout. ${ }^{[1]}$

Construction along the east Longhai economic belt, for Jiangsu butt "along the way" strategy and actively participate in the new eurasian continental bridge Economic Corridor is of great significance. ${ }^{[2]}$ Governor of Jiangsu Xueyong Li (2015) pointed out that the focus of the "along the way" strategy is to raise the economic radiation capacity of Xuzhou and Lianyungang, and the promotion of Huai'an, Yancheng, Suqian and other neighboring towns' positive response, active integrate and linkage development. ${ }^{[3]}$ Towns along the east Longhai mainly located in northern Jiangsu, whose economy is relatively backward, mainly because the backward economic development of Xuzhou and Lianyungang, which lack of strong radiation capacity for nearby cities, thus the important measures are to improve the integrated development capability of Xuzhou, Lianyungang, and expand the scope of radiation of the city, drive around the county's economic development, strive to build cities and towns along the east Longhai.

Firstly, the paper introduces the current situation of economic and social development of the region along the east Longhai from five aspects, such as spatial structure, economic position, natural resources, transportation system and cultural industries. Then, the paper compare the economic belt along the east Longhai with the economic belt along the Yangtze River from different index, the level of industrialization and the level of the comprehensive development of the region. Finally, with the background of the new economic normality, the paper put out some measures to strengthen the construction along the east Longhai economic belt mainly from industrial development, innovation-driven, structural optimization, financial configuration, public services, and coordination mechanisms.

\section{SITUATION OF ECONOMIC AND SOCIAL}

\section{DEVELOPMENT IN THE AREA ALONG THE EAST LONGHAI}

Areas along the east Longhai include Xuzhou, Lianyungang and Pizhou, Xinyi, East China Sea from the perspective of administrative. As of 2013, the area of this region about 10,232 square kilometers, the resident population about 8.37 million yuan, GDP about 457.631 billion yuan, accounting for $9.97 \%, 10.54 \%, 7.74 \%$ of Jiangsu respectively, and per capital GDP was 60,660 Yuan, the added value ratio between first industry, secondary industry and tertiary industry is 7.04: 44.58: 48.38 . Construction along the east Longhai economic belt is a major strategy to blend in the OBOR for Jiangsu, will play an important role in the development of northern Jiangsu and even the whole socio-economic development. The characteristics of the regional economic development are as follows.

- Spatial structure. The region's spatial structure is mainly characterized by dual-core model that is a trend of complementary advantages between Xuzhou (the central city of Huaihai economic zone) and Lianyungang (a port city). This kind of "dualcore-type" spatial structure can promote the development of surrounding cities, expand the influential range of central cities, and will become 
a driving force for the development of northern Jiangsu, even the whole province.

- Economic location. Areas along the east Longhai are located in the northernmost of Jiangsu and between the Bohai rim and the Yangtze river delta, connect Japan, South Korea across the sea on the east, link the vast central plains and western regions on the west, is connected to the economic center of Shanghai on the south, and joint China's political and cultural center of Beijing on the north, its economic advantage is obvious.

- Resource endowments. The natural environment and living conditions of this area is better. Land, freshwater, non-metallic mineral and marine resources are more abundant, especially the nonagricultural land is suitable for development. In addition, the region has a solid education foundation, profound cultural background, and abundant labor resources, and is good at the field of mining, machinery, marine, agriculture and so on.

- The traffic system. Longhai railway and Lianhuo highway traverse the district from east to west, Beijing-shanghai railway and Beijing-shanghai expressway run through the north and the South, and with the Beijing Hangzhou grand canal, Lianyungang port, Xuzhou, Pizhou two inland port, Xuzhou Guanyin airport and Lianyungang Baitaibeng port and LuNing pipeline, the area has a relatively complete land, sea and air traffic system. ${ }^{[4]}$

- Culture Industry. The region along the east of Longhai steeped in history, it has a rich cultural heritage, especially Han culture in Xuzhou, and Lianyungang's landscape culture, historical culture and so on. Xuzhou, Liubang's birth place, with 400 years of history and culture, known to us for Han culture. Lianyungang has rich cultural elements, both historical and cultural city Haizhou, there are a modern green city Xinpu, and a more modern seaside town.

\section{COMPARISON OF THE ECONOMIC BELT ALONG THE EAST LONGHAI AND ALONG THE YANGTZE RIVER}

Along the Yangtze River economic belt including six major cities, such as Nanjing, Zhenjiang, Yangzhou, Changzhou, Taizhou, Nantong and 15 cities and counties in the surrounding area. In 2013, the area has a population of 4140.97 million, an area of 48,660 square kilometers, GDP 4.768368 trillion, accounting for $52.2 \%$, $47.43 \%$, $80.80 \%$ of Jiangsu Province respectively. Thus, although the socio-economic development of the east of Longhai with a slight advantage in the area of the structure, economic position, natural resources, transportation systems, and cultural aspects of the space industry, but there are significant disparities between the economic belt along the east of Longhai and along the Yangtze River economic belt in terms of economic fundamentals, or the future potential of the current development. The main differences are as follows.

\section{A. The Main Difference on Economic Indicators}

As can be seen from TABLE I, both in GDP, or in the total retail sales of social consumer goods, total imports and exports and expenditure, there is a big gap between the economic belt along the east of Longhai and along the Yangtze River.

TABLE I. MAIN INDEX COMPARISON ON THE YANGTZE RIVER ECONOMIC BELT AND THE ECONOMIC BELT ALONG THE EAST LONGHAI

\begin{tabular}{|c|c|c|c|c|c|}
\hline Index & $y_{1}$ & $y_{2}$ & $y_{3}$ & $y_{4}$ & $y_{5}$ \\
\hline$x_{1}$ & 59161.75 & 47683.68 & 0.81 & 4576.31 & 0.08 \\
\hline$x_{2}$ & 74607.00 & 96407.00 & 1.29 & 60660.00 & 0.81 \\
\hline$x_{3}$ & 20796.60 & 16318.09 & 0.78 & 1559.17 & 0.07 \\
\hline$x_{4}$ & 5508.00 & 5244.03 & 0.95 & 109.32 & 0.02 \\
\hline$x_{5}$ & 7798.47 & 4718.71 & 0.61 & 622.27 & 0.08 \\
\hline
\end{tabular}

$x_{i}(i=1,2,3,4,5)$ represents GDP, the per capita GDP, the total retail sales of social consumer goods, the total imports and exports and the fiscal expenditure respectively. $y_{i}(i=1,2,3,4,5)$ represents the whole province, the Yangtze River economic belt, economic belt along the Yangtze river accounted for the proportion of Jiangsu, economic belt along east Longhai and economic belt along the east Longhai accounted for the proportion of Jiangsu respectively.

$$
y_{3}=\frac{y_{2}}{y_{1}} \quad \text { (1) } \quad y_{5}=\frac{y_{4}}{y_{1}}
$$

\section{B. Differences on the Level of Industrialization}

Economic belt along the Yangtze River started early, and with high level of industrialization. The structure of the three major industries is 3.36: 50.75: 45.89, indicating that industrialization along the Yangtze River economic belt has entered a medium-term development. Meanwhile, the industrial structure along the east of Longhai is 7.04: 44.58: 48.38, compared with the economic belt along the Yangtze River, the first industry accounted for a major, the level of industrialization is still in the initial stage of development, but its industrialization process has a significant acceleration trend, has a greater potential for development, is an important economic growth in Jiangsu.

\section{Differences on Regional Comprehensive Development of Central City}

This paper select index mainly from six aspects, such as the economic strength, the level of science and technology, the financial system, infrastructure, the condition of service industry, and agriculture development, to study the differences on regional comprehensive development of central city along the East Longhai economic belt and along the Yangtze River economic belt by factor analysis. We determine two public factors F1, F2 according to the rules that the characteristic value $>1$ and the cumulative contribution rate $>80 \%,{ }^{[5]}$ where $\mathrm{F} 1$ is a public factor in urban economy, science and technology 
level, F2 is a public factor which reflects the scale of urban infrastructure, the level of service industry and the level of agricultural development. According to the rotation matrix (omitted), the original variables can be expressed by the public factor F1 and F2, as shown below.

$$
x_{i}=\alpha_{1} \times F_{1}+\alpha_{2} \times F_{2} \quad \text { (3) }
$$

$x_{i}$ represents the various indicators respectively, $\alpha_{1}, \alpha_{2}$ represents the matrix coefficient after rotation, $F_{1} 、 F_{2}$ are public factors.

Finally, the SPSS software is used to calculate the individual public factor score, and we take variance contribution of each factor accounted for the proportion of total variance contribution rate as weight to calculate the comprehensive score $\mathrm{F}$, that is

$$
F=\left(74.953 \times F_{1}+16.556 \times F_{2}\right) / 91.509
$$

Ranking for each city, and the final ranking results are shown in TABLE II .

TABLE II .THE MAJOR CITY RANKINGS ON THE ECONOMIC BELT ALONG THE EAST LONGHAI AND ALONG THE YANGTZE RIVER

\begin{tabular}{|c|c|c|c|c|c|c|}
\hline \multirow{2}{*}{ City } & \multicolumn{2}{|c|}{ F1 } & \multicolumn{2}{c|}{ F2 } & \multicolumn{2}{c|}{ Composite } \\
\cline { 2 - 7 } & Score & Ranking & Score & Ranking & Score & Ranking \\
\hline Nanjing & 2.023 & 1 & 0.644 & 3 & 1.774 & 1 \\
\hline Xuzhou & 0.588 & 2 & -1.440 & 7 & 0.221 & 2 \\
\hline Changzhou & -0.258 & 3 & 1.144 & 1 & -0.005 & 3 \\
\hline Yangzhou & -0.514 & 6 & 0.093 & 4 & -0.404 & 4 \\
\hline Taizhou & -0.477 & 4 & -0.091 & 5 & -0.407 & 5 \\
\hline Zhengjiang & -0.873 & 7 & 0.855 & 2 & -0.560 & 6 \\
\hline Lianyungang & -0.490 & 5 & -1.206 & 6 & -0.619 & 7 \\
\hline
\end{tabular}

As can be seen from TABLEII, the regional comprehensive development level of Xuzhou is higher, but there is still a gap compared with the Nanjing. Lianyungang has a larger gap compared with cities along the Yangtze River economic belt, neither on the aspect of economic strength, level of science and technology, or the aspect of the construction of infrastructure, service level, and agriculture development. Overall, the center cities along the Yangtze River economic belt are relatively backward.

\section{CONCLUSION}

In summary, there is a big gap between the economic belt along the East Longhai and the Yangtze River on the aspects of index system, level of industrialization and urban center area comprehensive development level, main reason is that, economic belt along the Yangtze river with more perfect urban system, but the quantity of the towns along the east Longhai are few, and central city regional integrated development capability weak, radiation driven capacity is insufficient, hindered the region's urban social and economic development. Therefore, the important of promoting the construction of economic belt along the east Longhai is to create a vibrant urban axis, the main idea is to enhance regional comprehensive development capacity in Xuzhou and Lianyungang, promote the economic development of Pizhou, Xinyi, the east China Sea and others. Build large cities as the core, mediumsized cities as the backbone, the center cities as support in the east Longhai urban development axis, to achieve the interaction of urbanization and industrialization. ${ }^{[6]}$

\section{COUNTERMEASURES ON THE CONSTRUCTION OF ECONOMIC BELT ALONG THE EAST LONGHAI UNDER THE BACKGROUND OF THE NEW ECONOMIC NORMALITY}

Since 2014, our government has been advocating the new economic normality, that is, the economic growth from high growth to middle high growth, industrial structure optimization and upgrading, innovation driven to replace the investment and the elements driven. China has entered a new economic normality, but under the new normal framework, due to the construction of enterprises, the way of increasing industrial agglomeration to stimulate economic growth is often accompanied by environmental pressures, overcapacity of real estate bubble and so on. Therefore, it is the high time to change the original macro management ideas.

Industrial belt along the east of Longhai upgraded to economic zone reflect the change on the way of stimulating economic growth from the single industrial agglomeration to industry development, innovation driven, structural optimization and other diversified transformation, so it is a measure to actively integrate into the 'along the way' strategic for Jiangsu. According to current economic strength, industrial distribution and comparative advantage on the area along the east Longhai, we determine the focus of economic belt construction along the east Longhai is to enhance Lianyungang and Xuzhou as the two major growth pole in the contraction of economic along east longhai, to revitalize the regional development of Pizhou, Xinyi and Donghai, to form Industry Intensive zone and axis of urban development along the east Longhai, to accelerate the construction of eight major development zone in Xuzhou and Lianyungang, and to form industrial clusters. [4] The paper put forward suggestions and countermeasures on the construction of economic belt and how to create the urban axis is full of vitality along the east Longhai mainly from six aspects, such as the industrial development, innovation driven, structure optimization, financial allocation, public service and coordination mechanism construction.

\section{A. Promote the Development of the Industrial Area along the East Longhai}

Industrial development is the core content of the economic belt construction along the east Longhai, mainly from the following several aspects.

\section{1) Increase Government Support on Industrial} Development

The government should continue to increase support for the development of strategic emerging industries and high-tech industries. One is to accelerate the reform of the field, create a good environment for development and to 
provide government policy support for the construction of development Zone, the land requisition, the infrastructure, the project construction and so on. The second is to establish fiscal system more conducive to the construction of East Longhai Economic Zone, give tax preference, the provincial budget for special funds for infrastructure investment and discount on technological renovation and other oblique arrangement. The third is the combination of regional policy and industrial policy, to accelerate the development of technological innovation and industrial clusters, to strengthen the organization and implementation of strategic emerging industries, and to ensure the development of the six key industrial clusters and the rise of emerging industries. ${ }^{[7]}$

2) Give Full Play to the Comparative Advantages of Industrial Development in Xuzhou and Lianyungang

On the background of the macro-economy at home and abroad, the economic development of Xuzhou has entered a key stage of economic transformation, industrial optimization and layout adjustment. For Xuzhou, first, we should give full play to the leading role of XCMG, and to make the equipment manufacturing industry bigger and stronger. Second, give full play to the advantages of agricultural resources, and vigorously develop food, agricultural and sideline products processing industry. Third, make full use of the existing industrial base, and vigorously develop the energy industry. Fourth, give full play to regional advantages, and vigorously develop business logistics tourism.

For Lianyungang, it should give full play to their own advantages of the port, such as large flow of people, logistics quantity, and the amount of capital to promote the development of economy. At the same time, Lianyungang will be built into an international port of city by vigorously developing the non-public sectors of the economy, actively introducing foreign capital and the comprehensive expansion of two-way open range land and sea.

\section{B. Enhance Innovation Driven}

1) Focus on Enhancing the Innovation Ability of the Center City, Improving the Level of Regional Science and Technology

In Lianyungang, we need to speed up the construction process of major projects, such as petrochemical integration, to promote the new material industrial park, national high tech industrial base and the construction of innovation drug characteristics of the provincial base. ${ }^{[8]}$ In Xuzhou, we need to make full use of development zones as a platform to integrate into the "One Belt and One Road" for Jiangsu, to do a good job of west open strategy, and to improve the regional level of science and technology innovation by building up a high level of Xuzhou economic development zone, Xuzhou high-tech zones, mines science and Technology Park.

2) Speed up the Training of Innovative Talents, to Provide a Source of Motivation for the Innovation

National Science and Technology leading talentdriven innovation center was established at the end of 2014 will be based on the industry characteristics in the northern area of Jiangsu. Around the needs of business innovation, selection of the national science and technology leading military personnel to service in northern Jiangsu, we need to do meticulous technological innovation chain, promote the combination of production and research, collaborative innovation and scientific and technological achievements to a higher level of development, all-round to promote the realization of scientific research platform, high-tech enterprises, talent team, scientific and technological achievements. Therefore, we can achieve a major technological breakthrough in scientific and technological innovation and industrial development, and enhance regional innovation capability.

\section{Optimization of Regional Structure along the East Longhai Economic Belt}

On the one hand, based on the construction of "three city" positioning, we should focus on the construction of bigger and stronger center city. Xuezhou as the center of Huaihai economic zone, firstly, we should promote the construction of Huaihai urban agglomeration by scientific plan, to promote the development of the surrounding area. Further strengthen the close cooperation with the region of the city, trying to achieve greater better results on Huaihai urban agglomeration. Secondly, we should vigorously promote the interconnection of infrastructure on Xu and Lianyungang, accelerate the construction of the new Eurasian Continental Bridge railway, and actively promote the sea-river joint transport, air and land transport services, to improve the connectivity with the countries along the way. ${ }^{[9]}$

On the other hand, the implementation of "east" is to expand the development of new space inside and outside, and to dock large port for big cities. The promotion of "west" is to excavate co-operational opportunities with the countries along the New Eurasian Continental Bridge. In addition, we should fully play the construction platform of the "one belt and one road", do a good job in emerging industries and industrial convergence zone development demonstration zone, strengthen regional economic integration, trade facilitation, improve economic efficiency, optimize regional linkage development mechanism.

\section{Improve the Efficiency of Financial allocation}

1) The Establishment of Special Funds for Economic Zone Construction and Regional Cooperative Banking System

In order to change the present situation, such as many kinds of policy, decentralization of funds, we must set up special funds for the construction of economic belt along the east Longhai, to promote the regional economic development in a virtuous circle. In addition, through the adjustment of the capital stock, the establishment of East Longhai economic with special funds for the development of the construction industry, we can integrate the existing policy, especially industrial development funds policy. On the basis of existing cooperation with the east Longhai economic and financial development, the local 
government should form regional cooperation in the banking system gradually in accordance with the laws of economic development, and give full play to the advantages of financial cooperation, to provide a strong development of the East Longhai Economic Belt funding.

2) Build a Scientific Transfer Payment System, Extend Multiple Financing Channels

Adhere to the principle of common management of the government and the market, the government should establish a scientific financial transfer payment system, reform and improve the financial and policy of the supply mechanism, in increasing the financial and investment in policy, but also to strictly control the direction of investment funds, the system of financial management system, to enlarge the radiation intensity of limited funds, to provide a strong impetus to the economic development. In addition, we need to support for private investment, reduce private investment admittance threshold, to attract more private capital to participate in the belt along the east Longhai industrial building.

\section{E. Strengthen Infrastructure Construction, Improve Public Service Capacity}

Lianyungang as the first node cities on the new Eurasian Continental Bridge Economic Corridor and the urban center along the east Longhai economic belt should focus on strengthening the region's transportation infrastructure, to make a wide range interoperability of transport facilities. At the same time, take the advantages of the port, focus on the construction of China-kazakhstan logistics cooperation basis, and take full use of the radiation of the basis.

Xuzhou is an important transportation hub, and connected with the surrounding towns on the aspects of various funds, logistics, trade and others, so it is important to strengthen urban infrastructure construction for the improvement of Xuzhou economic strength, the measures are as follows. Firstly, strengthen the infrastructure construction of colleges and universities. Secondly, strengthen the construction of rural infrastructure. Thirdly, increase the investment in urban public service.

\section{F. Establish Coordination Mechanism, Promote the Development of Dual Core Interaction}

Xuzhou, Lianyungang, as the core cities along the east Longhai economic belt, although the two regional comprehensive development ability is relatively backward, but two cities has complementary, can give full play to the complementary advantages of both of the center city function, together to improve their regional comprehensive level, enhance the radiation to the surrounding towns, and build towns axis along the east Longhai.
1) Enhance Exchanges and Cooperation between Xuzhou and Lianyungang

First of all, Lianyungang is the bridgehead of the new Eurasian Continental, and the special geographical advantages give Lianyungang its important strategic in "along the way". Secondly, Xuzhou is a significant traffic hub in our country as well as a central city in Huaihai economic zone, providing better condition for Lianyungang to perform its strategic function at a large scale, wild range and high platform. Xuzhou and Lianyungang are connected, giving the two cities equal strategic status, and making the infrastructure and resources of two cities related and penetrated through multi-regional cooperation, as well as enhancing the complementary of economic development. ${ }^{[10]}$

2) Give Full Play to the Function of Sea-Land Combined Transportation of Continental Bridge

We suggest that Lianyungang should establish the continental bridge port offices in Xuzhou, so the service function of Lianyungang will extend to Xuzhou, to give full play to the inter-modal function of land bridge. In order to accelerate the development of export-oriented economy service between the two places, we need to open land and sea transport in Xuzhou - Japan and South Korea, Xuzhou - Central Asia, Xuzhou - European countries.

\section{REFERENCES}

[1] Xiaohua Song, Jiangsu focused on creating economic belt along the east Longhai [N], Xinhua Daily, 2015-8-2 (001).

[2] Zhilai Zheng, "convergence path and countermeasures on strategy of one way and one road for Jiangsu," Science \& Technology Progress and Policy, Vol. 32, No. 17, Sep. 2015, pp. 48-51.

[3] Implement the "one way and one road" strategy and enhance the level of regional development along the East Longhai, Retrieved May 7, 2015, from http://leaders.people.com.cn/.

[4] Zhushun, "The spatial characters and coordination of city and town belts in northern Jiangsu: based on the perspective of Land Space,' J. Of Jiangsu Normal Uni. Vol. 39, No. 4, Jul, 2013, pp. 127-131.

[5] Xiaoqun He, Multivariate Statistical Analysis [M], Beijing: Rennin University press, 2008.

[6] Yingming Cheng, Wanglie, Jiangsu to build a new pattern of Construction of economic belt along the east Longhai $[\mathrm{N}]$, China Industry News, A04, 2015-9-2.

[7] Xiaoyun Li, Chuangeng Zhu, Fangdao Qiu, “On multi-cooperation of the industrial belt along east longhai and the development zone along YangZe river in Jiangsu province," Economic Geography, Vol. 25, No. 6, Nov., 2005, 783-786.

[8] "Lianyungang city integrates into the construction of core cities for one belt and one road in Jiangsu", http://leaders.people.com.cn/.

[9] Lina GAO, Jianghui Yan, "Optimize the spatial structure along the east Longhai industrial belt," Regional Economy, No.12, 2009, pp. 27-29.

[10] Gu Xuan, Gu Long gao, "Ideas and countermeasures in bridge economic corridor construction along the east Longhai area," Continental Bridge Perspective, No. 11, 2015, pp. 42-49.

*This work is partially supported by Jiangsu university philosophy and social sciences fund project (2014 sjb406) (China) 